\title{
Energetic state and the continuum of migratory tactics in brown trout (Salmo trutta)
}

\author{
Birnie-Gauvin, Kim; Larsen, Martin H.; Aarestrup, Kim
}

Published in:

Canadian Journal of Fisheries and Aquatic Sciences

Link to article, DOI:

10.1139/cjfas-2021-0025

Publication date:

2021

Document Version

Peer reviewed version

Link back to DTU Orbit

Citation (APA):

Birnie-Gauvin, K., Larsen, M. H., \& Aarestrup, K. (2021). Energetic state and the continuum of migratory tactics in brown trout (Salmo trutta). Canadian Journal of Fisheries and Aquatic Sciences, 78(10), 1435-1443. https://doi.org/10.1139/cjfas-2021-0025

\section{General rights}

Copyright and moral rights for the publications made accessible in the public portal are retained by the authors and/or other copyright owners and it is a condition of accessing publications that users recognise and abide by the legal requirements associated with these rights.

- Users may download and print one copy of any publication from the public portal for the purpose of private study or research.

- You may not further distribute the material or use it for any profit-making activity or commercial gain

- You may freely distribute the URL identifying the publication in the public portal 
8

\title{
Energetic state and the continuum of migratory tactics in brown trout (Salmo trutta)
}

\author{
Accepted for publication in Canadian Journal of Fisheries and Aquatic Sciences
}

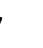

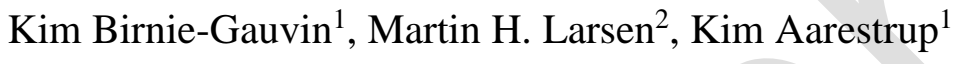

${ }^{1}$ DTU Aqua, National Institute of Aquatic Resources, Section for Freshwater Fisheries Ecology, Technical University of Denmark, Vejlsøvej 39, 8600 Silkeborg, Denmark

2 Danish Centre for Wild Salmon, Brusgårdsvej 15, 8960 Randers, Denmark

17

8
kbir@aqua.dtu.dk 


\section{Abstract}

Alternative migratory tactics, like partial migration, are common in many taxa. The proximate and ultimate drivers underpinning these strategies are unclear, though factors like condition and energetic status have been posited as important predictors. We sampled and PIT tagged 1882 wild brown trout prior to the first so-called decision window, and explored the links between migratory tactics (residency, autumn or spring migration) and body metrics (length and condition), lipids (triglycerides and cholesterol), and sex, in 150 randomly selected individuals. We found that more females adopted the autumn and spring migration tactic than males, while more males adopted the residency tactic than females, likely reflecting sex-biased benefits in anadromy. We also found that autumn migrants were in poorer condition prior to the presumed first decision window than spring migrants and residents. Lastly, we found that both condition and cholesterol were positively correlated to the timing of migration, such that individuals in poorer condition and/or with lower cholesterol migrated earlier. Collectively, these results suggest that energy depletion is an important factor in determining migratory strategy, including timing.

Keywords: cholesterol, partial migration, phenotypic plasticity, residency, triglycerides

47




\section{Introduction}

Life history strategies are ultimately the means by which an individual can maximize its fitness (i.e., number of descendants and genes passed on; McNamara and Houston, 1996; Thorpe et al., 1998). Migratory organisms can thus exploit heterogeneities between spatially separated environments to maximize their fitness. For example, organisms may move between environments that provide optimal feeding opportunities and optimal reproductive success, though migrating between both environments is energetically costly and can be risky (Gross et al., 1988; Alerstam et al., 2003). In fishes, anadromy (i.e., freshwater spawning individuals that migrate to sea to feed) is most prevalent in temperate regions, where marine habitats are more productive than freshwater habitats, whereas catadromy (i.e., marine spawning individuals that migrate to freshwater to feed) is most prevalent in tropical regions, where freshwater habitats are more productive than marine habitats (Gross et al., 1988). The occurrence of partial migration, whereby both migratory and resident phenotypes coexist within the same population, is also relatively common in fishes and other animal taxa (Chapman et al., 2011). Despite its widespread occurrence across taxa, fundamental gaps remain in our understanding of what proximately and ultimately drives partial migration.

Partial migration is well recognized in brown trout (Salmo trutta, Jonsson and Jonsson, 1993; Cucherousset et al., 2005), brook trout (Salvelinus fontinalis, Morinville and Rasmussen, 2003) and rainbow trout (Oncorhynchus mykiss, McPhee et al., 2007), and is thought to be driven by an interaction between environmental and genetic factors. The threshold model suggests that migration is dependent on whether a critical environmentally-sensitive status trait (e.g., physiological condition, size, energetic state) exceeds a predetermined genetic threshold at a certain developmental switch-point, where failure to exceed the threshold would result in migration (Hutchings and Myers, 1994; Thorpe and Metcalfe, 1998; Brodersen et al., 2008; Chapman et al., 2011; Ferguson et al., 2019). While the timing of this developmental switch-point (or decision window) is unknown in brown trout, it is hypothesized to be in late summer in Atlantic salmon (Salmo salar; Metcalfe et al., 1990), and is concurrent with the start of the smoltification process in both Atlantic salmon and brown trout migrants. As such, it is likely that the first decision window occurs some time in later summer for brown trout as well. A second decision window, thought to be in early spring (just before migration), determines whether the migration trajectory is continued or discontinued (Rikardsen et al., 2004; Ferguson et al., 2019). The threshold, given its genetic determination, is also likely to be influenced by sex given the presence of a sex bias in the benefits 
of migration and residency (Hendry et al., 2004). Despite considerable acceptance of the threshold model however, the factors that may predispose individuals to become migrants or residents remain largely unknown.

In brown trout, multiple migration tactics are common within the same population, exhibiting a sort of migration continuum that includes stream residents, fluvial and adfluvial potamodromous individuals (i.e., river and lake migrants), short-distance marine migrants and long-distance marine migrants (Klemetsen et al., 2003; Cucherousset et al., 2005; Boel et al., 2014; Bordeleau et al., 2018). More recently, acceptance for the presence of a class of autumn migrants has grown (Winter et al., 2016; Aarestrup et al., 2018; Birnie-Gauvin and Aarestrup, 2018), though observations of autumn migrants dates back to the 1980s (e.g., Youngson et al., 1983). It has been suggested that the adopted migratory tactic is related to intrinsic metabolic needs of individual trout (Cucherousset et al., 2005). In contrast to dichotomous migratory tactics, a migration continuum suggests the presence of behavioural responses to resource availability, which may change through space and time along the migratory route. Migratory tendency is negatively correlated with the costs (Bohlin et al., 2001) and distance of migration (Kristoffersen et al., 1994). For example, Boel et al. (2014) found that energetically depleted brown trout were more likely to migrate, and of migrants, those with lower triglycerides were more likely to abort seaward migration and become short-distance lake migrants. As such, the distance and duration of migration undertaken by an individual may be partly controlled by energetic status.

Vertebrates that undergo changes and adaptations relating to life history strategy can be characterized by a lipid storage phase, followed by a phase of depletion (Sheridan and Kao, 1998). In salmonids in particular, lipid depletion and alterations in lipid metabolism are a key aspect of the smoltification process (i.e., the process by which migrants prepare for their entry in seawater; Sheridan et al., 1983, 1985; Sheridan 1989). Prior to migration, available resources tend to be allocated toward protein anabolism, and not toward lipid storage as is the case for residents (Morgan et al., 2002). In salmonids, low energetic (nutritional) status can be characterized as low plasma concentrations of cholesterol, triglycerides, total protein, phosphorus and calcium (Congleton and Wagner 2006). Within this context, lipid status, as determined by plasma levels of cholesterol and triglycerides, is a likely indicator of migratory tactic in salmonids.

We currently still lack studies attempting to characterize the mechanisms that animals use to achieve the optimal life history pattern. To explore relationships between body metrics, energetic status, 
121 sex and migratory tactics, we sampled juvenile brown trout prior to the proposed first developmental 122 switch-point to characterize their lipid resources and monitored their life-history strategy using telemetry. 123 Samples were obtained before the migratory decision itself was made, thus allowing us to: 1) characterize 124 differences in status traits (length, condition, lipids) among three migratory phenotypes prior to the first 125 migratory decision window in both females and males; 2) explore whether these status traits and sex 126 influence migratory tactics; and 3) determine whether these status traits influence the timing of migration 127 among female and male migrants.

128

129

Methods

130

131

Study site

132

The Gudsø stream is located in the southeastern region of Kolding, Jutland, Denmark. The stream runs for $6 \mathrm{~km}$ before entering the Kolding fjord. It is home to a wild population of brown trout, with both migratory and resident phenotypes. The stream is equipped with two Passive Integrated Transponder (PIT) stations (S1 and S2), each equipped with two antennas, located approximately 150m from one each other, with the downstream-most station situated $500 \mathrm{~m}$ from the fjord outlet (Figure 1). Note that while fish could reside in the $500 \mathrm{~m}$ stretch between the downstream PIT station and the fjord, previous electrofishing surveys indicated that tagged fish did not reside there. All fish were tagged and released more than $1 \mathrm{~km}$ from the PIT stations.

\section{Capture, sampling, and tagging}

Between July 3 and 19, 2017, a total of 1882 fish were captured using electrofishing, netted, and immediately placed in a 60L container of fresh, oxygenated, stream water. Shortly thereafter, fish were transferred into a 400L tank with continuously flow of freshly oxygenated stream water. Subsequently, fish were anesthetized in $0.03 \mathrm{~g} \mathrm{~L}^{-1}$ benzocaine in fresh water until their ventilation rate had slowed significantly. Fish were then measured (total length, $\pm 0.1 \mathrm{~cm})$ and weighed $( \pm 0.1 \mathrm{~g})$ before being tagged with a 23mm PIT tag (Texas Instruments, RI-TRP-RRHP, 134 Hz, 0.6 g mass in air, Plano, Texas, USA). All fish had their adipose fin clipped to enable differentiation from non-tagged fish in the stream and for sexing (see below). Blood samples $(0.1 \mathrm{~mL})$ from the caudal vasculature were obtained using a 
1-inch 25-gauge heparinized needle, and centrifuged for 2 minutes immediately. Fish were then left to recover in a 500L container of fresh stream water, and released near their site of capture.

Fish captured in the study ranged between 11.0 and $18.9 \mathrm{~cm}$, but no scales were taken to age the fish. While it is possible that this size range reflects two year classes (1+ and $2+$ years), the length distribution of all captured individuals would seem to indicate otherwise (Figure 2). Given that fish were sampled in the summer, precocious maturity (especially common in males) could not be identified.

Between June 1 and June 8,2018, the entire stream was resampled by electrofishing to determine which individuals had assumed residency. All protocols were approved by the Danish Experimental Animal Inspectorate (2017-15-0201-01164).

\section{Determination of phenotypes and migration timing}

Data from the PIT stations were downloaded 1 June 2018, following the peak smolt migration period in Denmark. To be considered as migrants, fish had to be detected at one of the upstream and one of the downstream PIT antenna, in that order (to confirm directionality), and subsequently not detected for > 1 month to ensure the fish migrated. No fish returned between migration and the download of the PIT data on 1 June 2018. Migration date was considered as the date the fish was last detected on the downstream PIT station (after having been detected at the upstream station). Migration timing was subsequently calculated as the number of days between migration date and date of tagging (i.e., days post-tagging).

Fish detected to have left the stream between September and November were considered 'autumn migrants', while those detected to have left the stream between February and April were considered 'spring migrants'. Between 1 June and 8 June 2018, the Guds $\varnothing$ stream was resampled via electrofishing in its entirety to determine which individuals had become 'residents' (i.e., fish recaptured alive that did not leave the stream). Fish that were not detected to leave the stream nor recaptured during resampling nor predated (see below) were considered to have an 'unknown fate'. These fish are not considered in any analyses, but data on body metrics is presented in Table 1 .

We were also able to identify individuals that were predated by cormorants (Phalacrocorax carbo) by scanning nearby colonies with portable backpack PIT scanners. These were not considered separate phenotypes, but data on body metrics is also presented for 'predated' individuals in Table 1. 
PIT station and electrofishing efficiency

PIT station efficiency for S1 (upstream station) was found to be $89 \%$, and calculated as follows

(Zydlewski et al. 2006):

$$
\text { Efficiency }_{S 1}=\frac{\text { detections }_{\text {common }}}{\left(\text { detections }_{S 2}+\text { detections }_{\text {common })}\right.} \times 100
$$

185

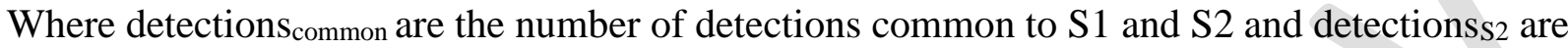
detections unique to S2. Note that the efficiency for S2 cannot be calculated. The PIT stations were operational throughout the entire period of the study as flow conditions did not change to a degree that would preclude functionality.

Electrofishing efficiency was estimated using the depletion method during the stream resampling in June 2018, using 3 stretches of 100m in varied locations across Guds $\varnothing$ stream (representing varied habitats). Briefly, each stretch was electrofished once, where all collected fish were kept in a bin. The stretch was immediately electrofished a second time. Electrofishing efficiency was estimated as $95.2 \%$, and calculated as follows:

$$
\text { Electrofishing efficiency }=\frac{N_{\text {pass } 1}-N_{\text {pass } 2}}{N_{\text {pass } 1}} \times 100
$$

Where $\mathrm{N}_{\text {pass } 1}$ is the number of fish captured on the first pass and $\mathrm{N}_{\text {pass } 2}$ is the number of fish captured on the second pass.

\section{Plasma energetic correlates and condition}

A random subsample of individuals were selected to assess plasma lipids and for sexing: 50 residents, and 100 migrants, spanning a migration date between August 2017 to May 2018. Thus, the subsample of 100 migrants included autumn migrants, spring migrants, as well as migrants that may have left the stream outside of the September-November and February-April periods. Plasma triglyceride levels were measured using a triglyceride colorimetric assay kit (Cayman Chemical Item No. 10010303). All samples were assayed in duplicates, and the average absorbance was used to extrapolate triglyceride concentration. Intra-assay variation was between 0 and $7.41 \%$, while inter-assay variation was $2.57 \%$. Plasma cholesterol levels were measured using a cholesterol fluorometric assay kit (Cayman Chemical Item No. 10007640). Samples were diluted 1:200, and assayed in duplicates. The average fluorescence 
of the duplicates was used to extrapolate cholesterol levels. Intra-assay variation was between 0 and $2.5 \%$, while inter-assay variation was $4.7 \%$. Both indices have previously been used as indicators of nutritional status in salmonids (Congleton and Wagner, 2006).

Condition was calculated as Fulton's $(\mathrm{K})$ using the following equation:

$$
K=\frac{\operatorname{mass}(\mathrm{g})}{\text { length }(\mathrm{cm})^{3}} \times 100
$$

\section{Sexing}

DNA from adipose fins was extracted using the Chelex method (Estoup et al., 1996) with Qiagen Multiplex PCR kits. All PCR amplifications were performed in a final volume of $6 \mu 1$ with $0.5 \mu 1$ template DNA and a concentration of $0.2 \mu \mathrm{M}$ for each primer. PCR reactions were conducted following the kit manufacturer's recommendation, using an annealing temperature of $57^{\circ} \mathrm{C}$ and 25 cycles. The PCR product was run on a Seq Studio Automated Sequencer, with Genemapper (version 4) for genotyping. Sexing was done using the sdY primer (Quéméré et al., 2014) with a peak presence at 180200 base pairs corresponding to males and the absence of a peak corresponding to females. Two other primers (ssa85 and SsOs1408) were used for positive control. Of the 150 selected samples, 147 were successfully sexed (3 samples could not be sexed due to poor DNA extraction results).

\section{Data analysis}

Statistical analyses were conducted on the 147 randomly selected individuals for which plasma triglyceride and cholesterol concentrations, and sex were available. One spring migrant had an abnormally high condition factor $(K=1.40)$, and was removed from the analysis, leaving 146 individuals for further analyses [98 migrants (including 41 autumn migrants, 44 spring migrants and 13 migrants that migrated outside the autumn and spring peaks) and 48 residents]. Data were inspected for homogeneity of variance and collinearity, where correlation coefficients $<0.70$ were considered acceptable. Length and mass were highly correlated (correlation coefficient $=0.96$ ), thus only length was used in the analyses.

To test for differences in length, condition, triglycerides and cholesterol among phenotypes (categorical, 3 levels: resident, autumn migrant and spring migrant) and sex (categorical, 2 levels: female and male), individual two-way analyses of variance (ANOVA) with Type III sums of squares 
were conducted for each response variable, including both main effects and interactions. Significant differences were evaluated by post hoc comparisons (Tukey-Kramer test). Differences in sex ratio among the three phenotypes was evaluated by a Chi-square analysis (goodness-of-fit test). Note that the 13 migrants that migrated outside the autumn and spring peaks (i.e., August, December, January and May migrants) are not included in these analyses to avoid overlap between the autumn and spring seasons.

To explore relationships between plasma lipid concentrations and migration timing (numerical, continuous variable), we used generalized linear models (GLM). All 98 migrants (i.e., autumn migrants, spring migrants and fish that migrated outside the autumn and spring) were included in this analysis, but residents (i.e., non-migrants) were not. We followed a step-by-step approach of model simplification from a full model (including length, condition, triglycerides, cholesterol and sex) based on the Akaike information criterion (AIC, Table 2). The GLM was fitted with a Gamma distribution and $\log$ link function. The best model fit suggested that length, condition and cholesterol should be retained as explanatory variables. The final model was as follows:

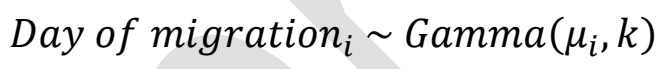$$
E\left(\text { Day of } \text { migration }_{i}\right)=\mu_{i}
$$

$$
\operatorname{var}\left(\text { Day of migration }{ }_{i}\right)=\frac{\mu_{i}^{2}}{k}
$$$$
\log \left(\mu_{i}\right)=\rho_{1}
$$

$$
\rho_{1}=\alpha+\beta_{1} \cdot \text { Condition }_{i}+\beta_{2} \cdot \text { Length }_{i}+\beta_{3} \cdot \operatorname{sqrt}(\text { Cholesterol })_{i}
$$

Where $\alpha$ is the intercept, and $\beta$ is the slope (Table 3). Note that square root transformations were applied to triglycerides and cholesterol data to satisfy underlying assumptions of normality and homogeneity of variance in residuals. All statistical analyses were performed using R version 3.6.3 ( $\mathrm{R}$ Development Core Team, 2020), using lattice (Deepayan, 2008), ggplot2 (Wickham, 2009) and MASS (Venables and Ripley, 2002) R packages.

\section{Results}

Of the 1882 tagged and sampled juvenile brown trout, 493 migrated, 96 assumed residency and 17 were detected at nearby cormorant colonies (Table 1). Fish migrated between 10 August 2017 to 23 
May 2018 (Figure 3), with the majority of fish migrating in spring (February-April: 302 spring migrants) and autumn (September-November: 124 autumn migrants), representing the two 'peaks' in migration typically observed in this river (Birnie-Gauvin and Aarestrup 2019). The remaining 1276 individuals had an unknown fate, and may have: 1) died in the stream, 2) been predated by herons and cormorants (colonies for both species are found nearby), 3) assumed residency but were not captured upon re-electrofishing of the stream, or 4) migrated but were not detected at the PIT antennas. The two latter options are less likely given our electrofishing efficiency of $95.2 \%$ and PIT detection efficiency of $89 \%$ at the S1 (Zydlewski et al., 2006; note that efficiency at S2 cannot be measured). Overwinter mortality can be high for brown trout, and is likely to account for many of the fish with unknown fate (Elliott, 1993; Midwood et al., 2015).

Within the 146 individuals selected for sexing as well as triglyceride and cholesterol analysis, 26 females and 15 males migrated in autumn, 33 females and 11 males migrated in spring, and 4 females and 44 males resided. Five (5) females and eight (8) males migrated outside of the autumn and spring peaks; these are not included in the ANOVA analyses, but are included in the analyses testing the effect of plasma lipids, body metrics and sex on migration timing (see GLM results below).

The sex ratio differed significantly from an even distribution (goodness-of-fit test, $\chi^{2}=47.046$, $\mathrm{df}=2, p<0.001$ ) such that significantly more males assumed residency than females, and more females migrated in the autumn and spring than males (Figure 4).

Length differed between sexes $(\mathrm{F}=8.909, \mathrm{df}=1, p=0.00341)$, with females being longer than males, but not among phenotypes $(\mathrm{F}=2.886, \mathrm{df}=2, p>0.05$, Figure 5). Condition differed among phenotypes $(\mathrm{F}=6.009, \mathrm{df}=2, p=0.00321)$, with autumn migrants having significantly lower condition factors than both spring migrants (Tukey: $p=0.0151$ ) and residents (Tukey: $p=0.0160$, Figure 5). Plasma triglyceride ( $\mathrm{F} \leq 0.5194, \mathrm{df} \leq 2, p \geq 0.5961)$ and cholesterol $(\mathrm{F} \leq 2.187, \mathrm{df} \leq 2, p \geq$ 0.1167) concentrations did not differ among phenotypes or between sexes (Figure 5).

Condition $(p=0.00358)$ and cholesterol $(p=0.0389)$ were significantly positively correlated to migration day (Table 3, Figure 6). Length was not significantly correlated to migration day ( $p=$ $0.119)$.

\section{Discussion}


295

296

297

298

299

300

301

302

303

304

305

306

307

308

309

310

311

312

313

314

315

316

317

318

319

320

321

322

323

324

Understanding the proximate and ultimate drivers of divergent phenotypes is a fundamental goal of evolutionary ecology (Naish and Hard, 2008). In the field of salmonid research, the drivers of facultative migration in brown trout have piqued the curiosity of researchers for decades. The threshold model has been useful in understanding (at least in part) the drivers of migratory decision in salmonids (Hutchings and Myers, 1994; Thériault et al., 2007). According to this framework, if an individual's status exceeds a genetically-determined threshold at a specific decision window (late summer), this individual should assume residency and mature in freshwater (Dodson et al., 2013; Ferguson et al., 2017, 2019). The model also suggests that a second decision window (late winter, early spring) exists, where size and/or energetic status must exceed another threshold for an individual to continue migration. Failure to exceed the threshold would lead to migration being deferred to the next season or later (Ferguson et al., 2019).

Studies that have explored the relationship between potential status traits (e.g., energetic status, size, condition, growth rate) and the decision to migrate have often been conducted under laboratory settings, where fish that turn silver are considered migrants and those that do not are considered residents (e.g., Sloat and Reeves, 2014; Archer et al., 2019). While this approach has merit, it does not necessarily reflect the natural conditions of the fish's home river, and generally does not reflect ratios of migrant to resident observed in nature. In addition, using visual cues like silver colouration as an indication of migration has been shown to be inaccurate (del Villar-Guerra et al., 2019). Studies have also tended to measure status traits sometime after the migratory decision itself (for example during the parr-to-smolt transformation), and thus may not accurately reflect the trait at the time the decision was made. In this study, we attempted to address some of these limitations by sampling individuals before the presumed first decision window occurs, using telemetry to track the true life-history strategy, and further included autumn migrants as an additional phenotype given its increasing acceptance as part of the salmonid lifecycle. While the exact timing of the first decision window is not known, observations suggest that both brown trout and Atlantic salmon (i.e., closely related species) start to smoltify at the end of the summer (e.g., Metcalfe et al. 1990). By sampling fish in July, we were able to explore energetic status prior to the first decision window.

Unsurprisingly, we found that more females migrated than males, and more males assumed residency than females. Given that female reproductive success is limited by gamete production, and thus by size, there is a sex bias in the balance of benefits of migration and residency (Fleming, 1996; 
325 Hendry et al., 2004; Quinn, 2018). Thus, females gain more by migrating to sea because they can attain larger sizes, and thus greater fecundity and egg size, in addition to attracting more mates and defend spawning sites better (Fleming and Reynolds, 2004). Male reproductive success in contrast tends to be limited by access to mates rather than gamete production (Fleming, 1998). They often mature as residents and can adopt a sneaking strategy where they fertilize eggs at a very small size (Gross, 1985; Jonsson and Jonsson, 1993). Those males may still adopt a migratory strategy later in life (Dellefors and Faremo, 1988; L'Abée-Lund et al., 1990), but little investigation has been conducted on this aspect, thus offering an interesting avenue for future research.

We found that on average, autumn migrants were in poorer condition prior to the first decision window than both residents and spring migrants. Fish in poorer condition may have higher metabolic demands and thus often adopt a migratory strategy to sustain their physiological demands (Sogard et al., 2012; Sloat and Reeves, 2014; Ferguson et al., 2017). In combination with the sex-biased benefits of anadromy, we may expect that females in poor condition have much to gain from migrating to sea earlier, and thus migrate in the autumn. However, we found no significant effect of sex on condition suggesting that low condition may drive both females and males to migrate in autumn. In addition, fish of low condition are less likely to survive harsh winter conditions, as resources - lipids in particular become increasingly depleted (Cunjak 1988). Migrating to sea earlier, despite making fish more susceptible to predation, provides greater food abundance and thus an opportunity to replenish resources. Food abundance at sea is however greater in spring compared to winter, and thus postponing migration provides the benefit of staying relatively safe from predation in freshwater for as long as possible, while maximizing the feeding opportunities at the time of migration. In this context, spring migrants also have much to gain from migrating to sea. Moreover, because these spring migrants were in better condition than autumn migrants at the time of the first decision window, they were more likely to survive harsh winter conditions in freshwater, and thus deferred migration to the spring. This decision is expected, given that migration is more costly and risky than residency (Gross, 1987; Brönmark et al., 2014; Schwinn et al., 2018). In contrast, residents typically mature earlier and tend to have lower metabolic costs than migrants due to lower metabolic rates, so a higher condition factor at the first decision window is concurrent with existing literature on the subject (Sloat and Reeves, 2014). Together, these findings support the threshold model, and suggest that condition prior to the first decision window may be a good predictor of, or an important factor affecting, migratory strategy 
though we suggest discriminating between autumn and spring migrants (Figure 7). Specifically, both autumn and spring migrants would fall below the threshold at the decision window, but we would expect autumn migrants to fall below spring migrants (i.e., a lower level of the status trait).

We found no differences in average lipid resources among autumn migrants, spring migrants and residents. This may suggest that lipid resources in general, or plasma triglycerides and cholesterol specifically, are not status traits, though this would be in disagreement with previous findings (Jonsson and Jonsson, 2005; Boel et al., 2014). However, a lack of difference in average lipid resources prior to the first decision window may not be surprising. This is because we are comparing average group values (of 41 to 48 individuals), but the threshold varies for each individual. For example, a value of ' $\mathrm{X}$ ' may be below the threshold of individual A, but may be above the threshold of individual $\mathrm{B}$. In this case, individual A would migrate, but individual B would assume residency, even if both have the same value for a specific status trait. In other words, the fact that we found no differences in triglycerides or cholesterol among the three phenotypes does not mean that these two lipid correlates are not components of a status trait, but instead may reflect that each individual has a different reaction norm/threshold to which it responds. This idea, though difficult to tackle, should be explored further to pinpoint the factors that determine individual thresholds. Experimental work may be particularly useful here, where genetic background, food availability, temperature, and other factors would need to be controlled for and experimentally manipulated (e.g., Archer et al. 2019). Alternatively, assessing an extensive suite of physiological measurements (e.g., metabolic rate, thermal performance, cardiac performance, blood parameters, etc.) across a range of environmental conditions may allow us to develop more accurate thresholds for individuals, and enable more accurate predictions about their lifehistory strategies by providing us with a better understanding of the factors that affect life-history decisions.

The hypothesis that energetic status plays a role in the migratory decision is supported by our finding that cholesterol and condition are correlated to the timing of migration. Specifically, we found that both plasma cholesterol and condition factor were positively correlated to the timing of migration, suggesting that individuals with lower cholesterol and poorer condition migrate earlier. The timing of migration, which is a strategy in itself, may be driven by low resource availability to maintain metabolic functions, and thus migration may be initiated when individuals reach a specific low threshold. Though timing was not investigated in their study, Boel et al. (2014) found that migrants had 
lower condition and lipid stores, and suggested that individuals adopting migratory strategies were energetically depleted before migrating. In another study, Bordeleau et al. (2018) found that sea trout that migrated farther to sea were in poorer condition, and that individuals with lower triglycerides remained at sea longer. Again, this would indicate that energy depletion drives migratory strategies such that more energy-depleted individuals are willing to take greater risks (like migrating instead of assuming residency, or going farther and/or staying longer at sea). Our findings support this hypothesis, as autumn migrants had lower condition than spring migrants and residents, and energy-depleted migrants (low condition and low cholesterol) migrated earlier. This is likely driven by a need to replenish energy stores, and may involve a willingness to undertake more risky strategies.

In conclusion, the present study demonstrates a link between two posited status traits (condition and lipids) and life-history strategies, thereby supporting the threshold model, even with the consideration of a 'new' autumn migrant phenotype. In addition, the study supports the notion that a link exists between metabolic costs and life-history strategies (Morinville and Rasmussen, 2003), that sex differences are likely at play as early as the first decision window, and that migration timing is likely driven (at least in part) by energy depletion. We contribute to the existing body of literature by providing valuable information on the endogenous mechanisms that drive the migration continuum in brown trout. Understanding these mechanisms, and the factors that affect them, can help conserve facultative migratory species currently declining worldwide, by helping to maintain intraspecific variability, and thus increasing resilience against global changes (Schindler et al., 2015)

\section{Acknowledgments}

We wish to thank Andreas Svarer for his invaluable help in the field. We also wish to thank two anonymous reviewers for their valuable comments. This study was supported by the European Regional Development Fund (Interreg, MarGen II Project, \#175806) and the Danish Net and Fishing License.

\section{Author contributions}

KBG, MHL and KA conceived the study. KBG and MHL performed the field work and sampling. KBG performed the laboratory analyses. KBG performed the data analyses and wrote the first draft of the manuscript. KBG, MHL and KA commented and edited the manuscript. 
415

416

417

418

419

420

421

422

423

424

425

426

427

428

429

430

431

432

433

434

435

436

437

438

439

440

441

442

443

444

\section{References}

Aarestrup, K., Birnie-Gauvin, K., \& Larsen, M. H. (2018). Another paradigm lost? Autumn downstream migration of juvenile brown trout: Evidence for a presmolt migration. Ecology of Freshwater Fish, 27, 513-516.

Alerstam, T., Hedenström, A., \& Åkesson, S. (2003). Long-distance migration: evolution and determinants. Oikos, 103, 247-260.

Archer, L. C., Hutton, S., Harman, L., O'Grady, M. N., Kerry, J. P., Poole, R., ... \& Reed, T. E. (2019). The interplay between extrinsic and intrinsic factors in determining migration decisions in brown trout (Salmo trutta): an experimental study. Frontiers in Ecology and Evolution, 7, 222.

Birnie-Gauvin, K., \& Aarestrup, K. (2019). A call for a paradigm shift: Assumed-to-be premature migrants actually yield good returns. Ecology of Freshwater Fish, 28, 62-68.

Boel, M., Aarestrup, K., Baktoft, H., Larsen, T., Søndergaard Madsen, S., Malte, H., ... \& Koed, A. (2014). The physiological basis of the migration continuum in brown trout (Salmo trutta). Physiological and Biochemical Zoology, 87, 334-345.

Bohlin, T., Pettersson, J., \& Degerman, E. (2001). Population density of migratory and resident brown trout (Salmo trutta) in relation to altitude: evidence for a migration cost. Journal of Animal Ecology, 112-121.

Bordeleau, X., Davidsen, J. G., Eldøy, S. H., Sjursen, A. D., Whoriskey, F. G., \& Crossin, G. T. (2018). Nutritional correlates of spatiotemporal variations in the marine habitat use of brown trout (Salmo trutta) veteran migrants. Canadian Journal of Fisheries and Aquatic Sciences, 75, 1744-1754.

Brodersen, J., Nilsson, P. A., Hansson, L. A., Skov, C., \& Brönmark, C. (2008). Condition-dependent individual decision-making determines cyprinid partial migration. Ecology, 89, 1195-1200. 
446 Brönmark, C., Hulthén, K., Nilsson, P. A., Skov, C., Hansson, L. A., Brodersen, J., \& Chapman, B. B. 447 (2014). There and back again: migration in freshwater fishes. Canadian Journal of Zoology, 92, 467448479.

449

450

Chapman, B. B., Brönmark, C., Nilsson, J. Å., \& Hansson, L. A. (2011). The ecology and evolution of 451 partial migration. Oikos, 120, 1764-1775.

452

453

Congleton, J. L., \& Wagner, T. (2006). Blood-chemistry indicators of nutritional status in juvenile 454 salmonids. Journal of fish biology, 69, 473-490.

455

456

Cucherousset, J., Ombredane, D., Charles, K., Marchand, F., \& Baglinière, J. L. (2005). A continuum 457 of life history tactics in a brown trout (Salmo trutta) population. Canadian Journal of Fisheries and Aquatic Sciences, 62, 1600-1610.

459

Deepayan, S. Lattice: Multivariate Data Visualization with R (Springer, 2008).

461

462

Dellefors, C., \& Faremo, U. (1988). Early sexual maturation in males of wild sea trout, Salmo trutta L., 463 inhibits smoltification. Journal of Fish Biology, 33, 741-749.

464

465

del Villar-Guerra, D., Larsen, M. H., Baktoft, H., Koed, A., \& Aarestrup, K. (2019). The influence of 466 initial developmental status on the life-history of sea trout (Salmo trutta). Scientific reports, 9, 1-13.

Dodson, J. J., Aubin-Horth, N., Thériault, V., \& Páez, D. J. (2013). The evolutionary ecology of 469 alternative migratory tactics in salmonid fishes. Biological Reviews, 88, 602-625.

471 Elliot, J. M. (1993). A 25-year study of production of juvenile sea-trout, Salmo trutta an English lake 472 district stream. In Production of Juvenile Atlantic salmon, Salmo salar, in Natural Waters (ed. R. J. 473 Gibson and R. E. Cutting), pp. 109-112. Canadian Special Publication of Fisheries and Aquatic 474 Sciences No. 118. Ottawa: NRC Research Press. 
476 Estoup, A. C. R. L., Largiader, C. R., Perrot, E., \& Chourrout, D. (1996). Rapid one-tube DNA 477 extraction for reliable PCR detection of fish polymorphic markers and transgenes. Molecular Marine 478 Biology \& Biotechnology, 5, 295-298.

479

480

Ferguson, A., Reed, T., McGinnity, P., \& Prodöhl, P. A. (2017). Anadromy in brown trout (Salmo 481 trutta): a review of the relative roles of genes and environmental factors and the implications for 482 management and conservation. In Sea trout: Management \& Science, pp. 1-40. Matador, 483 Leicestershire, UK.

484

485

Ferguson, A., Reed, T. E., Cross, T. F., McGinnity, P., \& Prodöhl, P. A. (2019). Anadromy, 486 potamodromy and residency in brown trout Salmo trutta: the role of genes and the environment. 487 Journal of Fish Biology, 95, 692-718.

Fleming, I. A. (1996). Reproductive strategies of Atlantic salmon: ecology and evolution. Reviews in 490 Fish Biology and Fisheries, 6, 379-416.

491

492

Fleming, I. A. (1998). Pattern and variability in the breeding system of Atlantic salmon (Salmo salar), 493 with comparisons to other salmonids. Canadian journal of fisheries and aquatic sciences, 55(, 59-76. 494

Fleming, I. A., \& Reynolds, J. D. (2004). Salmonid breeding systems. In Evolution Illuminated497 New York. Salmon and their relatives, A. P. Hendry \& S. C. Stearns (Eds.), pp. 264-294. Oxford University Press,

Gross, M. R. (1985). Disruptive selection for alternative life histories in salmon. Nature, 313, 47-48. 500

501 Gross, M. R. (1987). Evolution of diadromy in fishes. American Fisheries Society Symposium, 1, 14502 25. 
504 Gross, M. R., Coleman, R. M., \& McDowall, R. M. (1988). Aquatic productivity and the evolution of 505 diadromous fish migration. Science, 239, 1291-1293.

506

507 Hendry, A. P., Bohlin, T., Jonsson, B., Berg, O. K. (2004). To sea or not to sea? Anadromy v. non508 anadromy in salmonids. In A. P. Hendry \& S. C. Stearns (Eds.). Evolution Illuminated - Salmon and 509 their relatives (pp. 92-125). Oxford University Press, New York.

510

511 Hutchings, J. A., \& Myers, R. A. (1994). The evolution of alternative mating strategies in variable 512 environments. Evolutionary Ecology, 8, 256-268.

Jonsson, B., \& Jonsson, N. (1993). Partial migration: niche shift versus sexual maturation in fishes. Reviews in Fish Biology and Fisheries, 3, 348-365.

Jonsson, B., \& Jonsson, N. (2005). Lipid energy reserves influence life-history decision of Atlantic salmon (Salmo salar) and brown trout (S. trutta) in fresh water. Ecology of Freshwater Fish, 14, 296519301.

Klemetsen, A., Amundsen, P. A., Dempson, J. B., Jonsson, B., Jonsson, N., O'connell, M. F., \& Mortensen, E. (2003). Atlantic salmon Salmo salar L., brown trout Salmo trutta L. and Arctic charr Salvelinus alpinus (L.): a review of aspects of their life histories. Ecology of freshwater fish, 12, 1-59.

Kristoffersen, K., Halvorsen, M., \& Jørgensen, L. (1994). Influence of parr growth, lake morphology, and freshwater parasites on the degree of anadromy in different populations of Arctic char (Salvelinus alpinus) in northern Norway. Canadian Journal of Fisheries and Aquatic Sciences, 51, 1229-1246.

L'Abée-Lund, J. H., Jensen, A. J., \& Johnsen, B. O. (1990). Interpopulation variation in male parr maturation of anadromous brown trout (Salmo trutta) in Norway. Canadian Journal of Zoology, 68, 1983-1987.

McNamara, J. M., \& Houston, A. I. (1996). State-dependent life histories. Nature, 380, 215-221. 
534 McPhee, M. V., Utter, F., Stanford, J. A., Kuzishchin, K. V., Savvaitova, K. A., Pavlov, D. S., \& 535 Allendorf, F. W. (2007). Population structure and partial anadromy in Oncorhynchus mykiss from 536 Kamchatka: relevance for conservation strategies around the Pacific Rim. Ecology of Freshwater Fish, $53716,539-547$.

538

Metcalfe, N. B., Huntingford, F. A., Thorpe, J. E., \& Adams, C. E. (1990). The effects of social status on life-history variation in juvenile salmon. Canadian Journal of Zoology, 68, 2630-2636.

541

542

Midwood, J. D., Larsen, M. H., Boel, M., Aarestrup, K., \& Cooke, S. J. (2015). An experimental field evaluation of winter carryover effects in semi-anadromous brown trout (Salmo trutta). Journal of Experimental Zoology Part A: Ecological Genetics and Physiology, 323, 645-654.

Morgan, I. J., McCarthy, I. D., \& Metcalfe, N. B. (2002). The influence of life-history strategy on lipid metabolism in overwintering juvenile Atlantic salmon. Journal of Fish Biology, 60, 674-686.

548

Morinville, G. R., \& Rasmussen, J. B. (2003). Early juvenile bioenergetic differences between anadromous and resident brook trout (Salvelinus fontinalis). Canadian Journal of Fisheries and Aquatic Sciences, 60, 401-410.

552

Naish, K. A., \& Hard, J. J. (2008). Bridging the gap between the genotype and the phenotype: linking 554 555 genetic variation, selection and adaptation in fishes. Fish and Fisheries, 9, 396-422.

560 Quinn, T. P. (2018). The behavior and ecology of pacific salmon and trout (2nd ed.). Seattle, WA: 
563 R Development Core Team (2020). R: A language and environment for statistical computing. R

564 Foundation for Statistical Computing, Vienna, Austria.

565

566

Rikardsen, A. H., Thorpe, J. E., \& Dempson, J. B. (2004). Modelling the life-history variation of Arctic

567 charr. Ecology of Freshwater Fish, 13, 305-311.

568

569

Schindler, D. E., Armstrong, J. B., \& Reed, T. E. (2015). The portfolio concept in ecology and

570 evolution. Frontiers in Ecology and the Environment, 13, 257-263.

571

572

Schwinn, M., Baktoft, H., Aarestrup, K., Lucas, M. C., \& Koed, A. (2018). Telemetry observations of 573 predation and migration behaviour of brown trout (Salmo trutta) smolts negotiating an artificial lake.

574 River research and applications, 34, 898-906.

575

576

Sheridan, M. A. (1989). Alterations in lipid-metabolism accompanying smoltification and seawater

577 adaptation of salmonid fish. Aquaculture, 82,191-203.

578

579

Sheridan M. A., Allen, W. V., \& Kerstetter, T. H. (1983). Seasonal variations in the lipid composition 580 of the steelhead trout, Salmo gairdneri Richardson, associated with the parr-smolt transformation.

581 Journal of Fish Biology, 23, 125-134.

582

583 Sheridan M. A., Allen, W. V., \& Kerstetter, T. H. (1985). Changes in the fatty acid composition of 584 steelhead trout, Salmo gairdnerii Richardson, associated with parr-smolt transformation. Comparative 585 Biochemistry and Physiology B, 80, 671-676.

586

587

Sheridan, M. A., \& Kao, Y. H. (1998). Regulation of metamorphosis-associated changes in the lipid 588 metabolism of selected vertebrates. American Zoologist, 38, 350-368.

589

590 Sloat, M. R., \& Reeves, G. H. (2014). Individual condition, standard metabolic rate, and rearing 591 temperature influence steelhead and rainbow trout (Oncorhynchus mykiss) life histories. Canadian 592 Journal of Fisheries and Aquatic Sciences, 71, 491-501. 
593 Sogard, S. M., Merz, J. E., Satterthwaite, W. H., Beakes, M. P., Swank, D. R., Collins, E. M., ... \& 594 Mangel, M. (2012). Contrasts in habitat characteristics and life history patterns of Oncorhynchus 595 mykiss in California's Central Coast and Central Valley. Transactions of the American Fisheries 596 Society, 141, 747-760.

597

598

Thériault, V., Bernatchez, L., \& Dodson, J. J. (2007). Mating system and individual reproductive 599

600 success of sympatric anadromous and resident brook charr, Salvelinus fontinalis, under natural conditions. Behavioral Ecology and Sociobiology, 62, 51-65.

601

602

Thorpe, J. E., Mangel, M., Metcalfe, N. B., \& Huntingford, F. A. (1998). Modelling the proximate 603 basis of salmonid life-history variation, with application to Atlantic salmon, Salmo salar L.

604 Evolutionary Ecology, 12, 581-599.

605

606

607

Thorpe, J. E., \& Metcalfe, N. B. (1998). Is smolting a positive or a negative developmental decision?. Aquaculture, 168, 95-103.

608

609

Venables, W. N. \& Ripley, B. D. (2002). Modern Applied Statistics with S. Fourth Edition.

610

611

Wickham, H. (2009). ggplot2: Elegant Graphics for Data Analysis.

612

613

614

615

616

617

Youngson, A. F., Buck, R. J. G., Simpson, T. H., \& Hay, D. W. (1983). The autumn and spring

618 emigrations of juvenile Atlantic salmon, Salmo salar L., from the Girnock Burn, Aberdeenshire, 619 Scotland: environmental release of migration. Journal of Fish Biology, 23, 625-639.

620

621

622

Zydlewski, G. B., Horton, G., Dubreuil, T., Letcher, B., Casey, S., \& Zydlewski, J. (2006). Remote monitoring of fish in small streams: a unified approach using PIT tags. Fisheries, 31, 492-502. 
623 Tables

624 Table 1. Biometrics. Mean total length (cm), mass $(\mathrm{g})$ and condition (Fulton's K) ( \pm SD) for all tagged 625 migrant and resident brown trout (Salmo trutta), as well as trout that were predated by cormorants, and 626 individuals with an unknown fate. Samples sizes for each phenotype are presented in italics. Range for 627 biometrics is provided in brackets.

\begin{tabular}{lccc}
\hline Phenotype & Length $(\mathbf{c m})$ & Mass $(\mathbf{g})$ & Condition \\
\hline Migrants (493) & $13.3 \pm 1.3$ & $24.7 \pm 7.5$ & $1.0 \pm 0.07$ \\
Residents (96) & $(11.0-17.1)$ & $(12.7-52.2)$ & $(0.77-1.4)$ \\
& $13.1 \pm 1.2$ & $23.8 \pm 7.5$ & $1.0 \pm 0.06$ \\
Predated (17) & $(11.1-16.2)$ & $(13.2-50.7)$ & $(0.83-1.2)$ \\
& $14.2 \pm 1.8$ & $31.0 \pm 11.8$ & $1.0 \pm 0.10$ \\
Unknown fate (1276) & $(11.2-17.8)$ & $(15.3-56.5)$ & $(0.89-1.3)$ \\
& $(11.0-18.9)$ & $27.0 \pm 10.3$ & $1.0 \pm 0.07$ \\
\hline
\end{tabular}

628

629

630 631

Table 2. Model selection. Model selection process and composition of the best three fitting regression models (i.e., lowest AIC).

\begin{tabular}{|c|c|c|c|}
\hline Rank & Model structure & AIC & $\Delta \mathrm{AIC}$ \\
\hline 1 & $\begin{array}{c}\sim \text { Condition }+ \text { Cholesterol }+ \\
\text { Length }\end{array}$ & 1065.21 & 0.00 \\
\hline 2 & $\begin{array}{c}\sim \text { Condition + Cholesterol + } \\
\text { Length + Triglycerides }\end{array}$ & 1065.98 & 0.77 \\
\hline 3 & $\begin{array}{c}\sim \text { Condition }+ \text { Cholesterol }+ \\
\text { Length }+ \text { Triglycerides }+ \\
\text { Sex }\end{array}$ & 1067.54 & 2.33 \\
\hline
\end{tabular}


635 Table 3. Parameter estimates. Parameter of the best fitted model (lowest AIC) predicting migration 636 timing (number of day post-tagging) as a function of length $(\mathrm{cm})$, condition and cholesterol $(\mu \mathrm{M})$. The 637 model followed a Gamma distribution.

\begin{tabular}{lcccc}
\hline $\begin{array}{l}\text { Explanatory } \\
\text { variable }\end{array}$ & Coefficient & SE & t-statistic & p-value \\
\hline Intercept & 0.0119 & 0.00426 & 2.798 & 0.00631 \\
Length & 0.000337 & 0.000214 & 1.580 & 0.118 \\
Condition & -0.00960 & 0.00321 & -2.992 & 0.00358 \\
Cholesterol & -0.000618 & 0.000295 & -2.096 & 0.0389 \\
\hline
\end{tabular}

638

639

640

641

642

643

644

645

646

647

648

649

650

651

652

653

654

655

656

657

658

659

660 


\section{Figure captions}

662

663

Figure 1. Guds $\varnothing$ stream, southeastern Jutland, Denmark. The stream is equipped with two PIT stations 664 (S1 and S2), each with two antennas. A well-known cormorant colony (circle) is found nearby in 665 Kolding Fjord, where PIT tags from predated juvenile brown trout (Salmo trutta) can be found. 666

Figure 2. Size distribution of all tagged brown trout (Salmo trutta) captured between 3 and 19 July $6682017(n=1882)$.

669

670

671

672

Figure 3. Distribution of migration timing between August 2017 and May 2018, (A) divided by 5-day bins, and (B) divided by month. Fish migrated in all months of the year with two peaks, a larger peak in spring (February-April) and a relatively smaller peak in autumn (September-October). .

673

674

Figure 4. Sex ratios of autumn-migrating, resident and spring-migrating juvenile brown trout (Salmo 675 trutta).

676

677

678

Figure 5. Boxplot of autumn-migrating, resident and spring-migrating juvenile brown trout (Salmo

679 trutta) values of (A) length (cm), (B) condition, (C) plasma triglycerides (mg/dl, square-root

680 transformed), and (D) plasma cholesterol ( $\mu \mathrm{M}$, square-root transformed), separated by sex. The boxplot shows median values (black lines), the interquartile ranges (boxes) and the $10^{\text {th }}$ and $90^{\text {th }}$ percentiles 681 (vertical lines). Dissimilar letters denote significant difference in mean values as identified by Tukey682 Kramer post hoc test. We note that length (A) was affected by sex (but not phenotypes) such that 683 females tended to be larger than males.

684

685

Figure 6. Modelled migration day (days post-tagging) as a function of (A) condition and (B) plasma 686 cholesterol levels ( $\mu \mathrm{M}$, square-root transformed) (B) for female (grey) and male (black) migrating brown trout (Salmo trutta), according to the most supported model based on the AIC criterion. Models 688 suggest a positive relationship between condition and migration day for both females and males, as 689 well as a positive relationship between plasma cholesterol and migration day for both females and 
701

702

703

704

705

706

707

708

709

710

711

712

713

714

715

716

717

718

719

males. Note that for (A) length and cholesterol values were held at mean values; for (B) length and condition were held at mean values. Note also that day $100=17$ October.

Figure 7. Updated threshold model at the first decision window accounting for autumn migrants. At the time of the decision window, the level of the status trait for autumn migrants is expected to be lower than spring migrants. We note that the exact trajectories of the status trait before and after the decision window are not known (i.e. the status trait could increase, decrease or remain the same over time; it is the level of the status trait at the time of the decision window that will dictate whether the fish migrates, and when). Depicted trajectories are for illustrative purposes only and based off of the typical representation of the threshold model (e.g., Thorpe et al., 1998; Ferguson et al., 2019).

(1)


$720 \quad$ Figures

721

722 Figure 1.

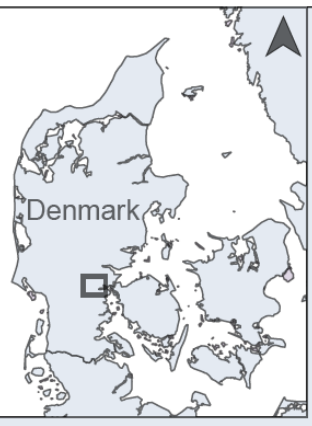

723

o $50010001500 m$

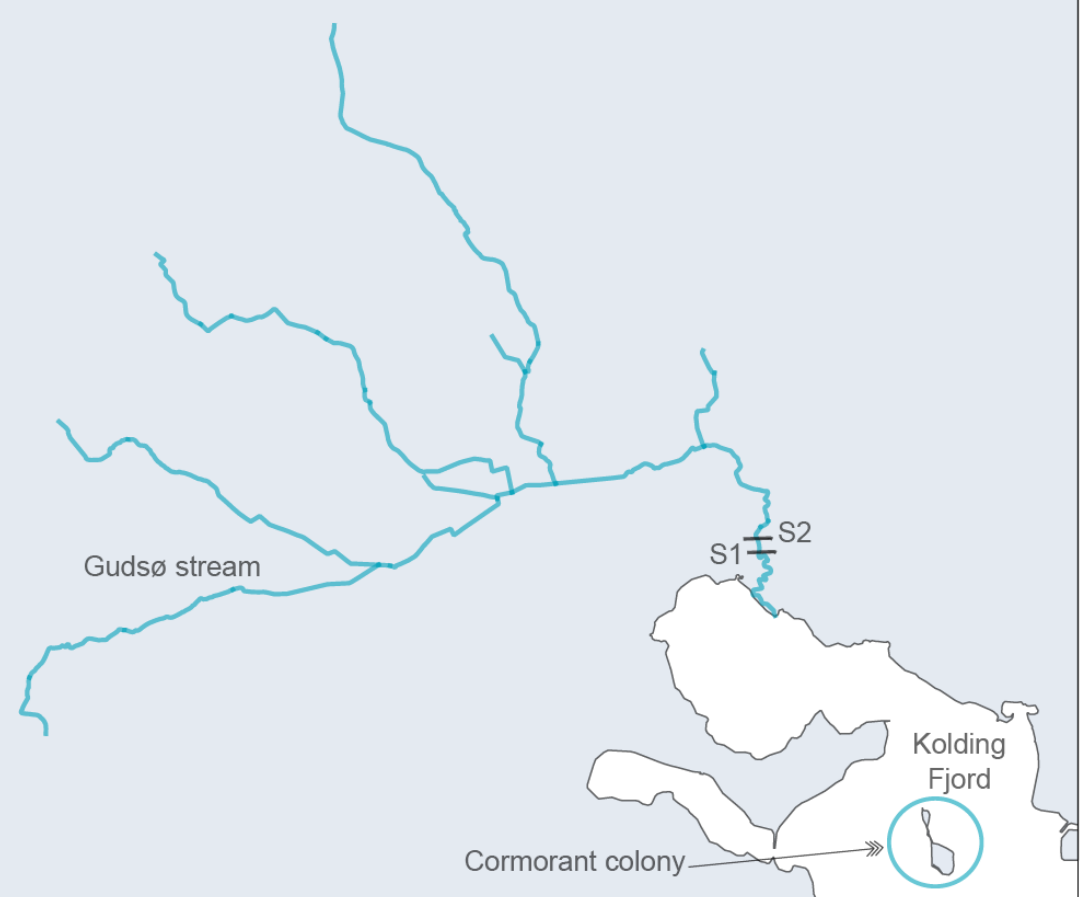

724

725

726

727

728

729

730

731

732

733

734

735 
$736 \quad$ Figure 2.

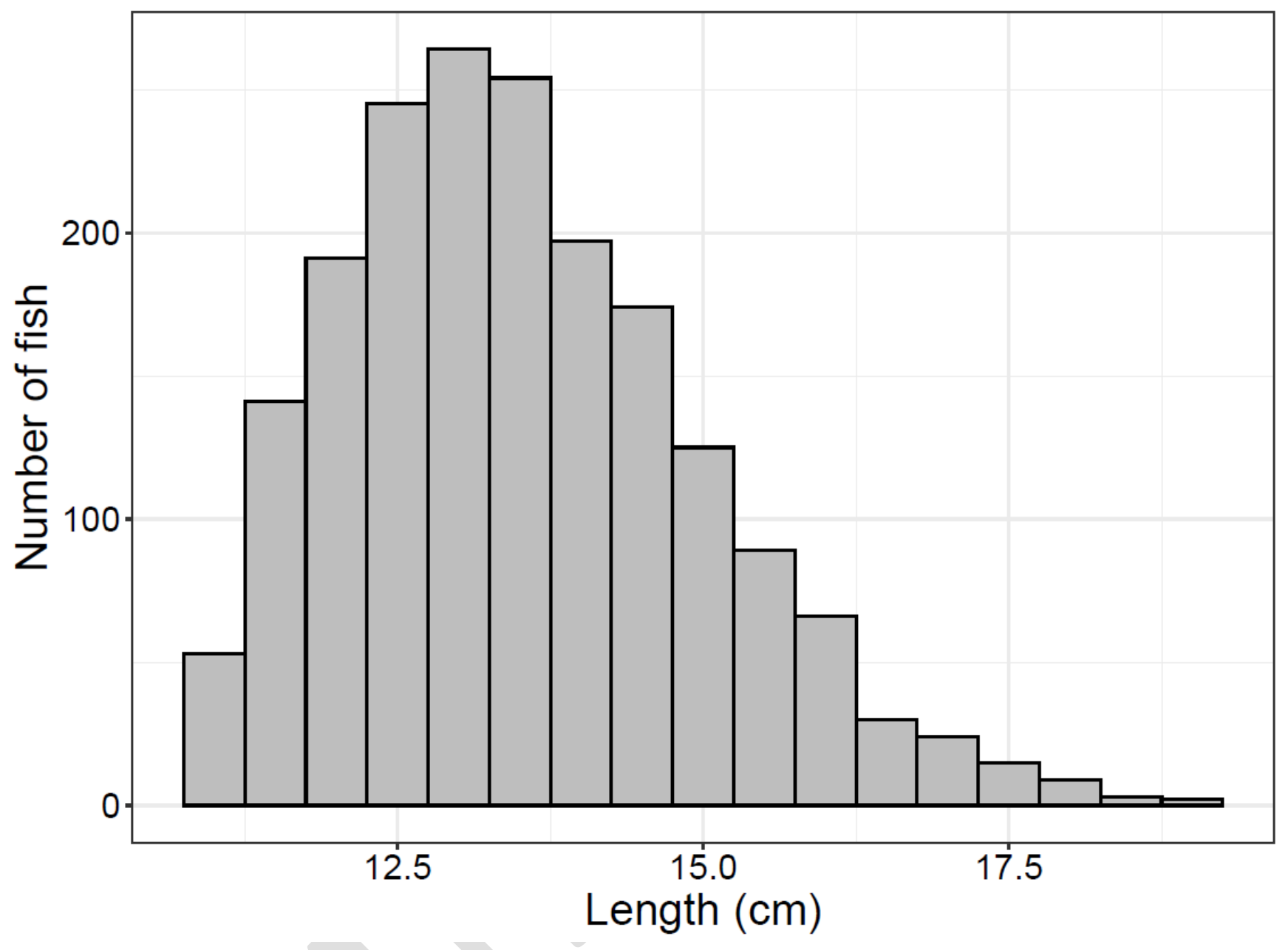

737

738

739

740

741

742

743

744

745

746

747

748 
Figure 3.
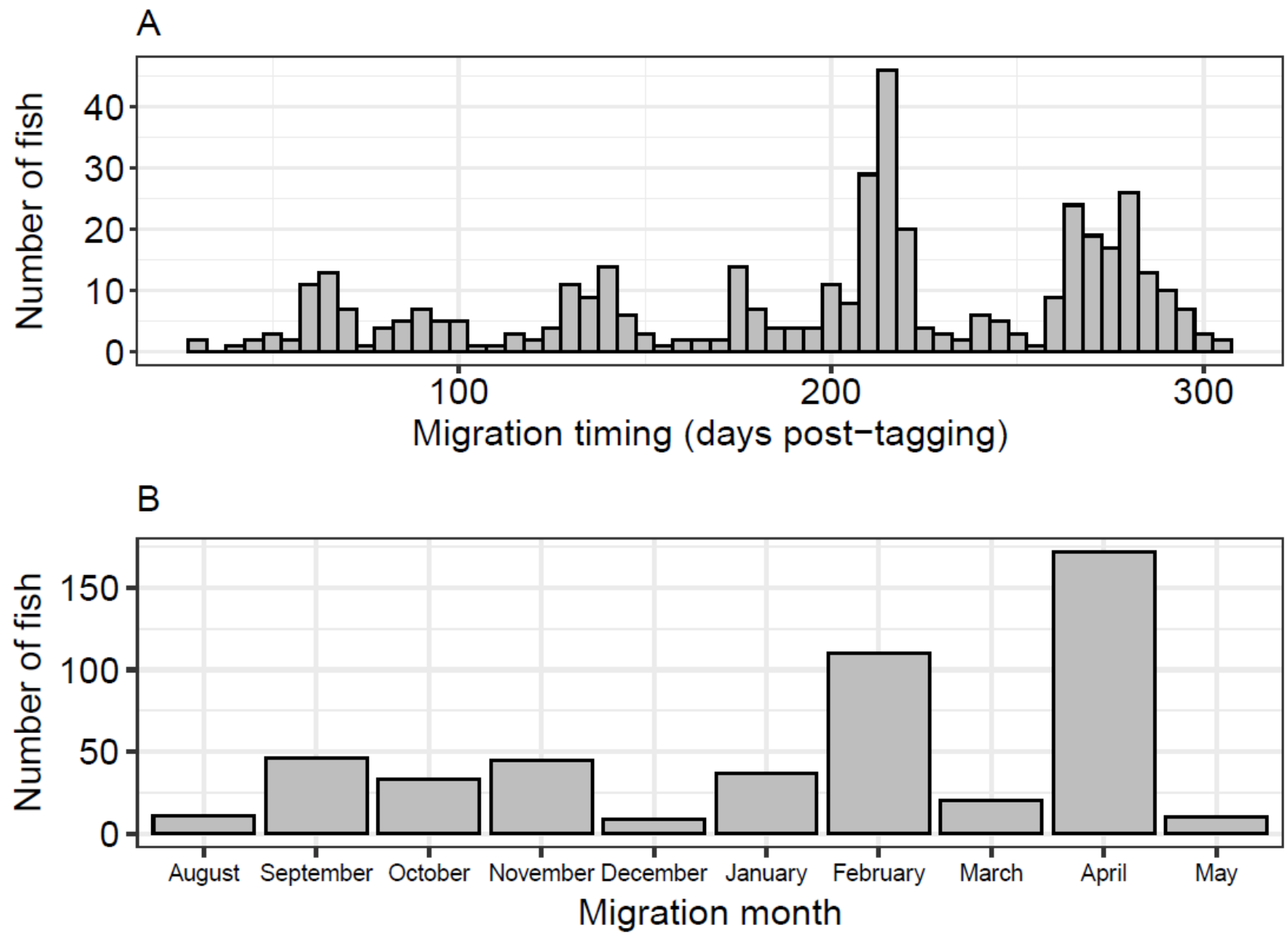

750

751

752

753

754

755

756

757

758

759

760

761 
$762 \quad$ Figure 4.

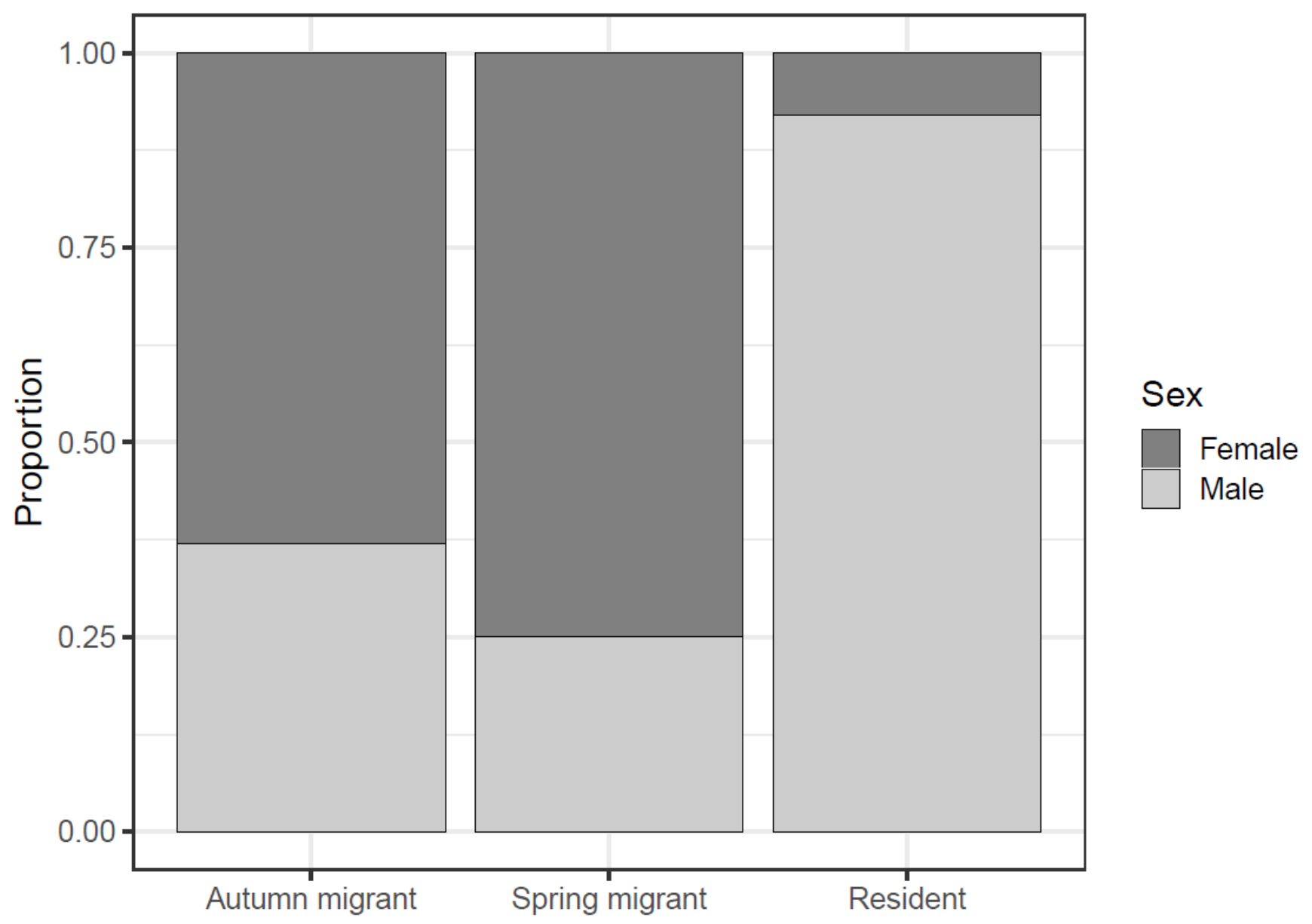

763

764

765

766

767

768

769

770

771

772

773

774 
$775 \quad$ Figure 5.
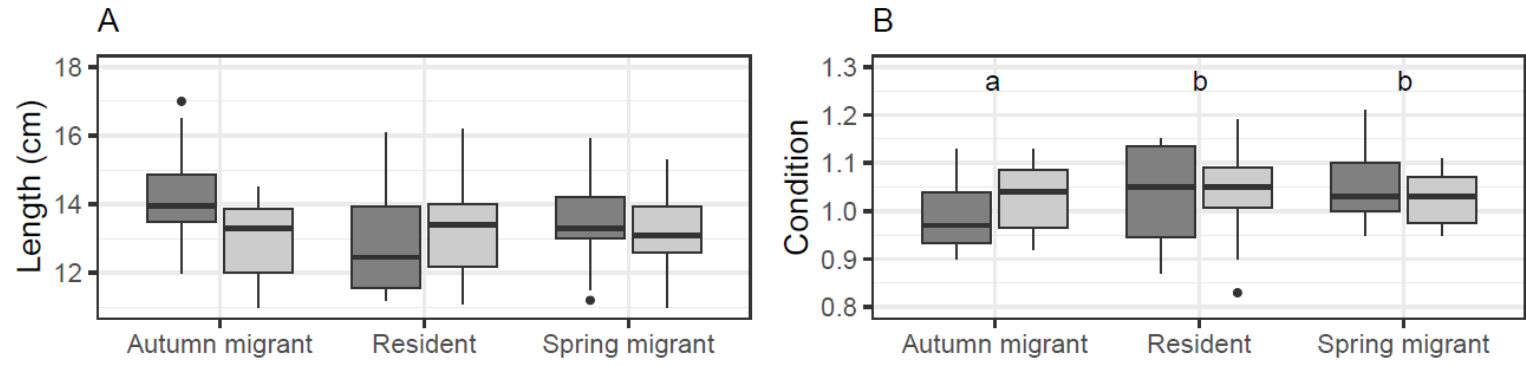

Sex

Female

官 Male
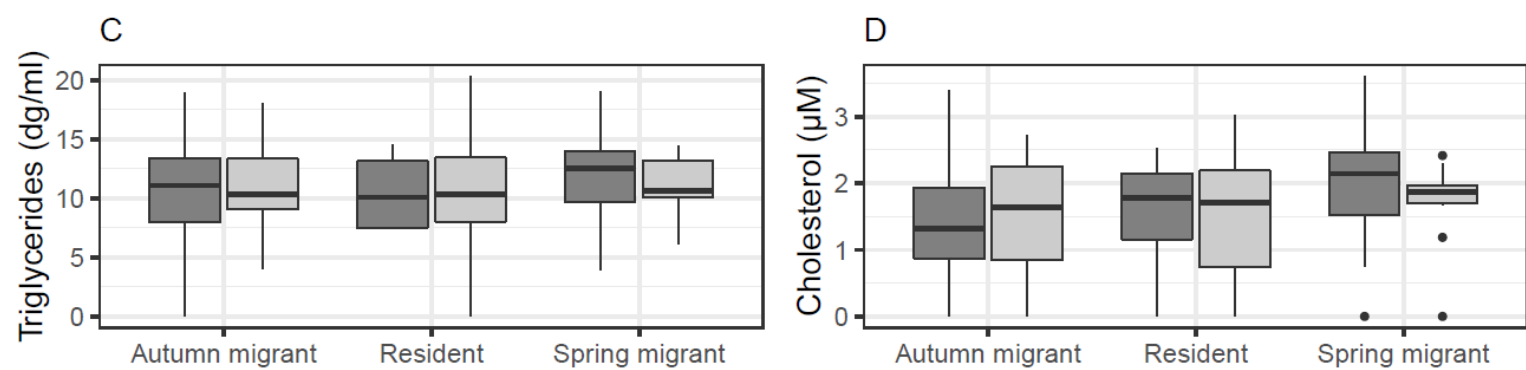

776

777

778

779

780

781

782

783

784

785

786

787

788

789

790

791

792

793 
$794 \quad$ Figure 6.

795
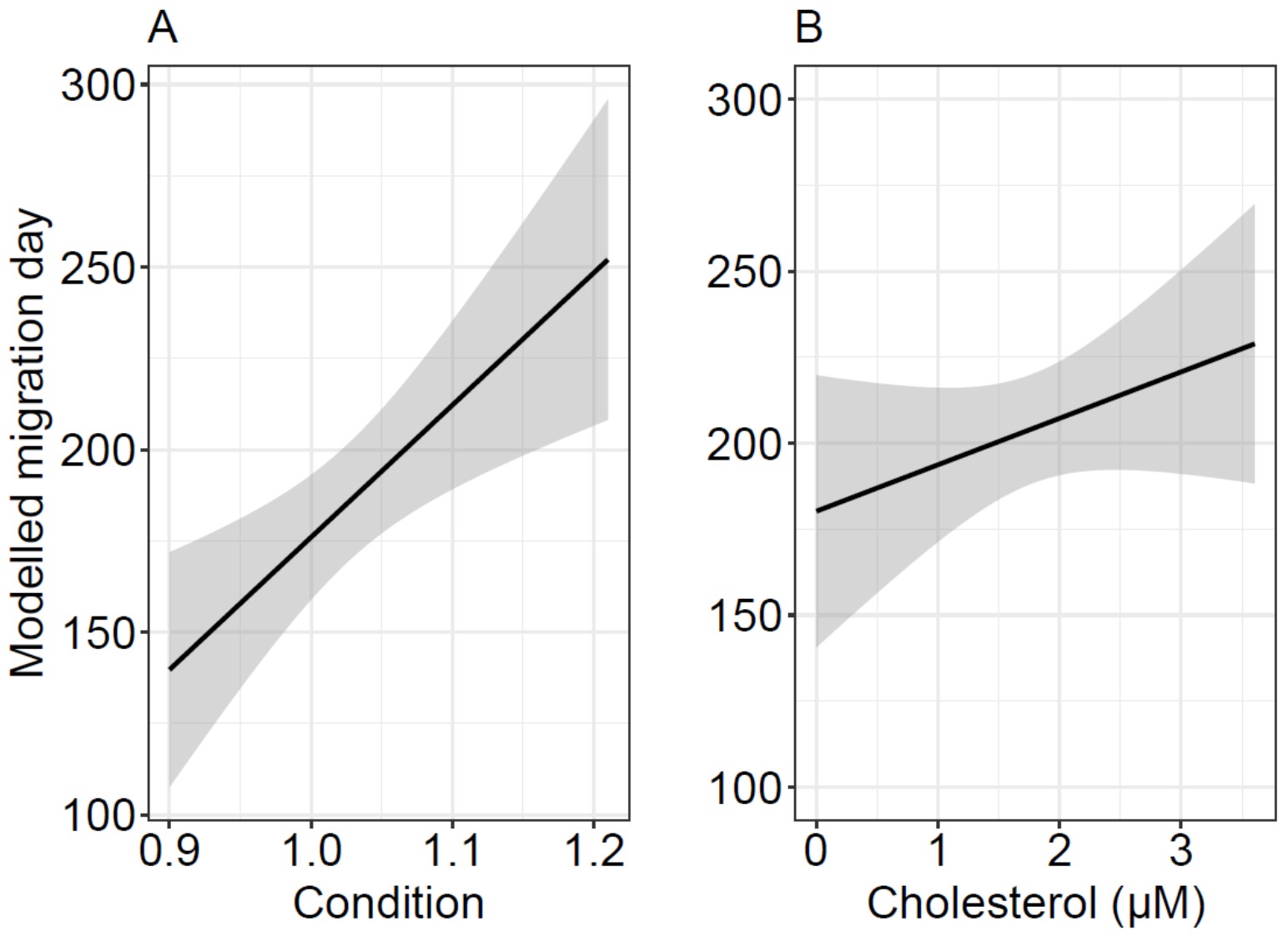

796

Figure 7. 


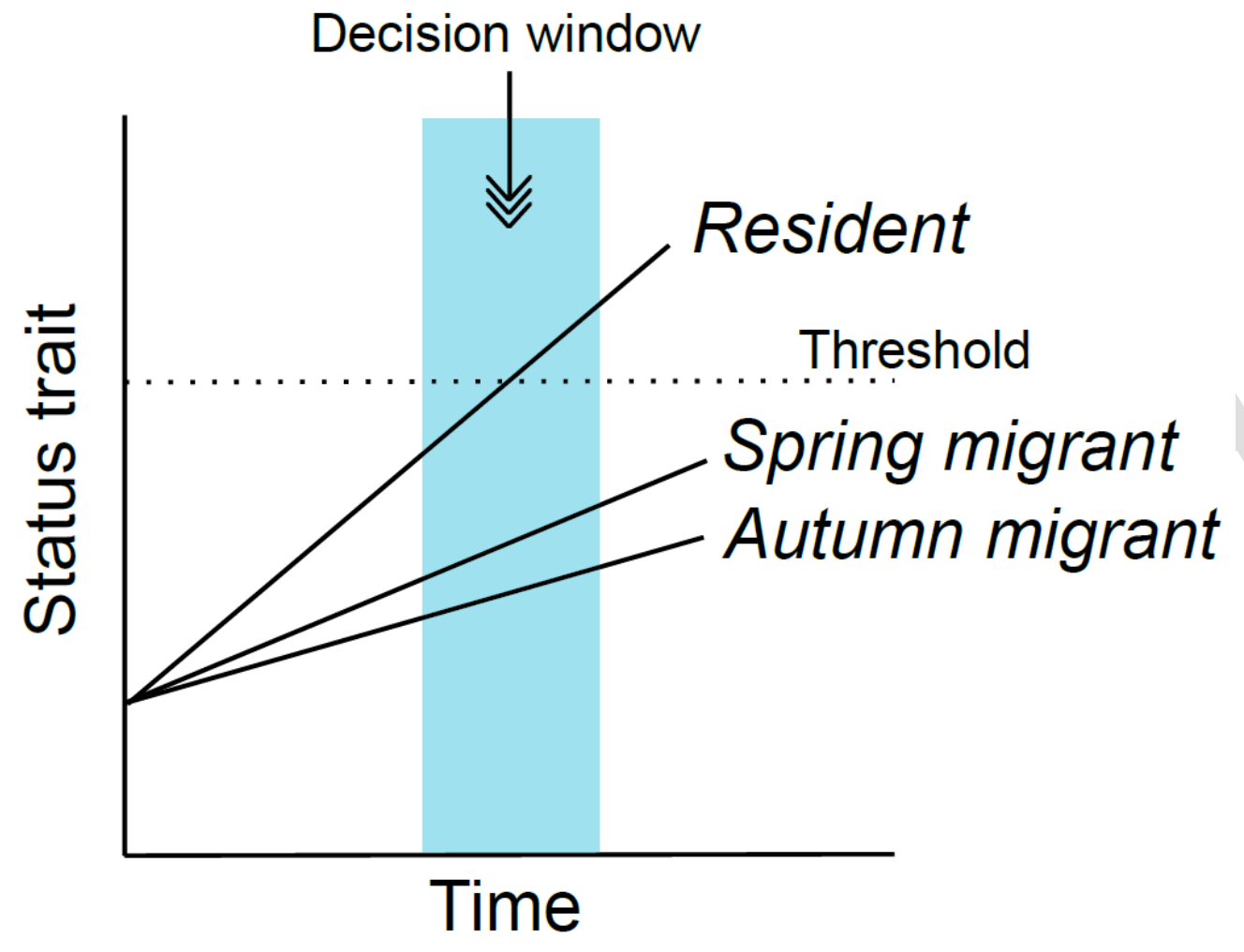

